\title{
ICT Based Learning Environments: What Are The Current Research Streams? Working Group 3.3
}

\author{
Chair: Rosa Maria Bottino (IT) \\ Rapporteur: Margaret Cox (UK) \\ Participants: Mette Andresen (DK), Ida Binderup (DK), Harald Bjar NO), \\ Tom Dousma (NL), Dick Owusu-Darko (UK), Katharine \\ Hayden (US), Pateep Methakunavudhi (TH), Philip Oppenheim \\ (DK)
}

Keywords: $\quad$ research, integration of ICT, catalyst for change, teaching, learning

\begin{abstract}
The growing use of ICT materials and tools was considered by the group in relation to key issues about how the evolving ICT based learning can be effectively integrated into different learning environment and subject areas. Participants considered three metaphors which represent the evolution of ICT based learning environments; namely, transmission, learner centred and participation. The main issues emerging from the discussion were a change in the whole learning situation (i.e., the tool, teacher, curriculum objectives and organisation of the learning process) as well as the effects and implication of factors affecting the learning environments. All these offer great opportunities and challenges which we believe requires research to establish and create a forum for a proper debate to resolve the issues concemed.
\end{abstract}

\section{ICT BASED LEARNING ENVIRONMENTS}

The focus of the group was on teaching and learning, concentrating on the mediation which ICT based learning systems can provide to the teaching and learning processes in the learning environment.

The professional group's work was supported by a briefing paper on the aims of the group and a background paper on advanced learning 
environments (Bottino 2001). The interests of the members ranged from primary to higher education, from the development of computer-based training materials to teacher education, and from the integration of pedagogical practices to the future roles of the teacher in new learning environments. These different interests led to a discussion of the perceptions of ICT based learning environments from the perspectives of the different countries of the participants and the different levels of education in which the participants were working. The purpose of this discussion was to consider the advantages and disadvantages of different learning environments, synthesizing the evolution of ICT based learning relating to three main metaphors and trying to determine the main elements characterizing this evolution.

Three metaphors were presented as a starting point for eliciting ideas about crucial issues in ICT based learning environments. These metaphors were:

1. Transmission: drill and practice, programmed learning, some web-based courses, and some computer based training courses

2. Learner centred: programming, microworlds, modelling and simulations

3. Participation: situated multi-tool system (integration of tools for different cognitive functions such as exploration, representation and communication), e.g. ICT based learning tools involving socialisation of the learner.

These metaphors can apply to the same software, for example a situated multi-tool system (participation metaphor) may also include microworlds (learner centred) and drill and practice (transmission). The discussion revealed some main elements that characterised the evolution of ICT-based education and its evolution (e.g. technological evolution, changed cognitive and pedagogical frameworks, changed role assigned to ICT-based systems in education, etc.). Three main issues emerged concerning ICT based learning environments:

1. ICT tools can influence and transform learning by fundamentally changing the content of a subject and the way in which it could be taught and learnt. When considering the design and use of such environments we need to consider the whole learning situation, for example, not only the tool, but the teachers who will be using the software, the ways in which it will be used, the curriculum objectives, the social context and way in which the learning is organised. This means that consideration needs to be given not only to the software design but also the definition of the possible ways it might be used effectively.

2. Learning strategies can influence the effectiveness of ICT design and use. The contrast between the structure and design of the learning environment may conflict with or support the individual learning styles 
of the learner. The ways in which the learning environment is used can change its original designers expectations; for example, there may be difficulties in accommodating different learning styles in the design of learning environments. Teachers can influence the learning strategies of the learner and thereby the ways in which ICT based learning environments are used.

3. Teaching and learning practices directly relate to the design and use of ICT based learning environments. We have to consider the fact that as ICT based learning environments change, the relationship between the factors above will also need to develop and change. For example, teachers might develop skills in organising individual use of ICT with their class of students, but when the opportunities increase for collaborative learning then the teacher will need to rethink the way in which he or she uses ICT within the subject and at a particular level.

\section{CURRENT PERSPECTIVES}

The main issues which the group considered to be important were identified according to new perspectives to be considered in the design of software based learning tools and the requirements from the teaching perspectives.

Requirements for the design of software based learning tools:

- The increasing scope for collaboration and communication needs to be considered when designing new software tools for subject based and cross-curricular based teaching;

- Software tools can be outside the conventional screen based applications and can be embedded in practical object based tasks, e.g. measurement and control;

- ICT tools should include where possible the facility for teachers to customize the learning activities according to the teaching and learning needs of their students;

- Software tools should include ideas about good pedagogical practice so that the user can make best use of the software;

- The design could be enhanced by examples of good pedagogical practices relating to learning theories and design principles, which could be used as guidelines for software development;

- Design of new tools should take into account of the value of non-text based activities. This means that not only should the software include, where appropriate, the use of pictures, figures, drawings, films and sound, but also it should enable the learners to interact with a variety of screen 
based objects to enable them to access knowledge from a different and more constructive perspective;

- ICT based tools should support the student problem solving processes and provide them with the opportunity to carry out open-ended problems, that is problems which do not have a closed defined answer.

- There should be the possibility of using different types of computing devices for learning, according to different teaching and learning needs. For example, the opportunities of lap-top and palm computers were discussed, pointing out their low cost and flexibility of use, compared with standard desk top computers.

These recommendations were considered in relation to the wider context of the teaching and learning environments, i.e. the teaching perspectives.

Requirements from the teaching perspectives:

- The teaching support and ICT learning resources need to be organised to sustain the enthusiasm of teachers for using ICT effectively;

- The initial training of teachers should incorporate techniques to show new teachers how to integrate ICT into their subject/curriculum areas;

- ICT resources should include materials which show how the activities support the learners' other activities;

- Teachers need to develop their pedagogical competencies to use ICT effectively in support of the learning goals;

- Professional school administrators (Senior management staff) need to be trained in the use of ICT in order to support, model and assess teachers' use of ICT in the classroom;

The group also considered factors that prevented the majority of teachers using ICT in their curriculum. Examples where ICT is used willingly and appeared to motivate the teacher to integrate it into their teaching included:

- The use of the WWW to access information to support subject based work

- The use of specific tools for specific purposes; e.g. in medical education

- The use of Office based software because of its vocational skills value.

Each of the participants had different knowledge and experiences of the barriers to the uptake and use of ICT in teaching and learning. These barriers were often linked to specific policies and practices of teachers within various education systems.

The issues and requirements previously discussed led to the identification of a range of research challenges. The reasoning behind the research issues identified is based on our original metaphors relating to ICT based learning environments. For example, in the case of the transmission metaphor then the group considered the role of the teacher having an effect on drill and practice software being used, and how the teacher's role might affect its contribution to learning. For the learner centred metaphor, then the 
participants pointed out that such type of software requires a change in the role of the teacher and the way in which the learning is organised in the classroom. Therefore research needs to be done to investigate how the classroom settings need to be changed to make ICT based learning effective. For the participation metaphor, a range of research issues were identified which reflected the complex nature and balance of the different components of the learning environment and how these would affect pupils' learning.

\section{RESEARCH CHALLENGES: TOWARDS A NEW VISION FOR LEARNING ENVIRONMENTS:}

Research challenges which were identified relating to the three main issues previously discussed: i.e. ICT tools to transform learning; learning strategies, and teaching and learning practices are given below.

- What are the cognitive functions that need to be considered when investigating the impact of new learning environments on teaching and learning processes?

- Which kinds of tools need to be integrated in advanced ICT based systems to support such cognitive functions?

- What kinds of learning strategies and outcomes are promoted by the diverse types of user interfaces and knowledge representations?

- How does the concept of an ICT-based learning environment change according to the different metaphor considered?

- How can models of best practice be defined?

- What are the most appropriate and effective ways of evaluating learning environments?

- How do ICT based learning environments affect the learning through collaboration and communication?

- What barriers affect the delivery and implementation of ICT in the curriculum, and how are these affected by the changing technology?

- What positive factors motivate teachers to use ICT and what support mechanisms need to be in place?

- What new models of teacher training lead to the long-term integration and sustained use of ICT in teachers' practice?

\section{REFERENCE}

Bottino, R. M. (2001) Advanced Learning Environments: changed views and future perspectives. In Computers and Education: towards an interconnected society, M. Ortega and J. Bravo (eds.), Dordrect, Kluwer, The Netherlands (in press). 